\title{
Menjadi Guru yang Siap di masa Pandemi Covid-19, Melalui Workshop Penggunaan Edmodo dan Google Classroom pada Pembelajaran Daring
}

\author{
Haris Kurniawan ${ }^{1}$, Eva Susanti ${ }^{2}$, Nurfisi Arriyani ${ }^{3}$

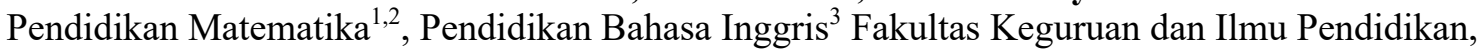 \\ Universitas Tamansiswa Palembang \\ Haris_kurniawan@unitaspalembang.ac.id
}

\begin{abstract}
ABSTRAK
Pembelajaran daring merupakan adaptasi dari pembelajaran tatap muka yang tidak bisa dilaksanakan semasa pandemi covid - 19, oleh karena itu mengkondisikan pembelajaran daring dengan baik tanpa merubah makna pembelajaran tatap muka adalah hal yang mesti di persiapakan oleh seorang guru. fasilitas pendukung yang merata yang dimiliki guru dan siswa di Faza Islamic school dan sekolah islam Ya Bunayya merupakan peluang yang sangat baik dalam mengkondisikan pembelajaran berbasis ini platform Learning Management System (LMS). Akan tetapi sebagian besar proses pembelajaran yang terjadi masih menggunakan media social. Tujuan diadakannya workshop ini adalah untuk membekali dan memberikan tambahan pilihan Platform dalam penerapan pembelajaran daring. Agar para guru dapat berinovasi dan berkreasi dalam proses pengajaran secara daring dimasa pandemi ini. Metode yang diberikan adalah dalam bentuk penyuluhan berupa workshop dan pendampingan penggunaan aplikasi Edmodo dan google classroom. Pesertanya adalah guru - guru di sekolah tersebut. kegiatan dilaksanakan pada tanggal 11 Juli 2020 pemberian materi, 12 - 18 Juli 2020 praktik dan pendampingan. Berdasarkan hasil kegiatan tampak antusiasme, kreasi dan inovasi guru dalam merancang pembelajaran secara daring, ditinjau dari hasil rancangan kelas yang mereka buat.
\end{abstract}

Kata kunci: Guru siap, Edmodo, Google classroom, covid - 19

\section{ABSTRACT}

Online learning is an adaptation of face-to-face learning that cannot be carried out during the COVID19 pandemic, therefore conditioning online learning well without changing the meaning of face-to-face learning is something that must be prepared by a teacher. Equitable support facilities that are owned by teachers and students at Faza Islamic school and the Ya Bunayya Islamic school are excellent opportunities in conditioning this learning-based Learning Management System (LMS) platform. However, most learning processes that occur still use social media. The purpose of this workshop is to equip and provide additional platform options in the application of online learning. So that teachers can innovate and be creative in the online teaching process in this pandemic. The method provided is in the form of counseling in the form of workshops and assistance using Edmodo and Google classroom applications. The participants are the teachers at the school. the activity was carried out on July 11, 2020, the provision of material, July 12-18, 2020 practice, and assistance. Based on the results of the activity, the enthusiasm, creation, and innovation of the teacher in designing learning online were seen, in terms of the results of the class design they made.

Keywords: Teacher ready, Edmodo, Google classroom, COVID - 19

\section{PENDAHULUAN}

Terkait kebijakan pemerintah berkenaan dengan pandemi COVID-19 di bidang pendidikan. Kementerian Pendidikan dan Kebudayaan membuat kebijakan pembelajaran tidak dilakukan secara tatap muka tetapi dilakukan secara tidak tatap muka.

Penyelenggara pendidikan dan pembelajaran di masa pandemi COVID-19, menerapkan sistem pembelajaran online sebagai pengganti pembelajaran tatap muka. Dengan tujuan untuk tetap menyelenggarakan pendidikan. Penyelenggara pendidikan tetap memiliki tanggungjawab yang besar kepada peserta didiknya agar memperoleh pendidikan meskipun dilakukan secara online. Salah satu penyelenggara jasa pendidikan yakni sekolah dasar dan menengah mesti beradaptasi pada proses pembelajaran di masa pandemic Covid- 
19 secara online dengan menggunakan beragam metode yang dinilai berkesesuaian dengan kultur akademik sekolah yang bersangkutan. (Santoso \& Santosa, 2020)

Penggunaan system pembelajaran online dalam pembelajaran merupakan implementasi dari pendidikan di era revolusi industry 4.0 (Pendidikan 4.0). Pendidikan 4.0 di tengah merebaknya wabah COVID-19, dapat diterapkan dengan penyesuaian tertentu tanpa menyampingkan hal-hal yang perlu diperhatikan lebih teknis, misalnya dampak dan kelemahannya. Pemahaman yang di transfer oleh guru di tuntuk agar dapat memberikan perubahan yang positif ditengah kondisi ini. Guru diharapkan dapat berkolaborasi dalam mewujudkan "kesempatan" mengabdi di tengah adanya pandemi ini. (Asih Theffidy, 2020)

Untuk memenuhi tuntutan tersebut, seorang guru hendaknya dapat mempersiapkan diri, sehingga mampu beradaptasi di era pendidikan 4.0 dan masa pandemi.. oleh sebab itu tidak sedikit persiapan yang mesti di lakukan oleh guru. beberapa di antaranya adalah : (1) mengetahui dan memahami kondisi lingkungan belajar. (2) Prinsip kebijakan pemerintah. Antara lain yakni kebebasan berinovasi dan prinsip merdeka belajar.

Setelah ke dua point tersebut dipahami oleh guru, maka persiapan pembelajaran yang mesti dilakukan adalah metode dan platform pembelajaran daring yang mesti dipilih. Pemilihan Platform dan metode ini sendiri mesti merujuk kepada point diatas.

Sebagian besar proses pembelajaran daring yang dilakukan saat ini masih memanfaatkan fasilitas grup Whatsapp dalam perangkat smartphone. Guru memberikan tugas kepada siswa melalui grup Whatsapp, baik melalui grup orang tua siswa maupun grup kelas masingmasing. (Arifa, 2020)

Sekolah Islam Ya bunayya dan Faza Islamic School merupakan salah satu sekolah yang sebagian besar proses pembelajaran daring yang dipakai menggunakan fasilitas grup whatsapp dalam perangkat smartphone. Dimana guru memberikan atau menyampaikan materi melalui grup berupa file video atau rekaman suara, lalu memberikan tugas kepada siswa melalui grup dan pengumpulan tugas dilakukan melalui whatsapp masing - masing guru.
Berdasarkan Edaran Mendikbud Nomor 4 tahun 2020, tentang pembelajaran jarak jauh dari rumah. Terdapat 4 point pokok pembelajaran yakni (1) memberikan pengalaman belajar yang bermakna bagi siswa. (2) fokus pada pendidikan kecakapan hidup antara lain mengenai pandemi COVID-19. (3) memberikan variasi aktivitas dan tugas pembelajaran. (4) memberikan umpan balik terhadap aktivitas belajar. (Kemdikbud, 2020)

\section{Prinsip Desain Pembelajaran Daring}

Beberapa prinsip desain yang harus dipenuhi agar menghasilkan pembelajaran daring yang baik, yaitu:

1. Identifikasi capaian pembelajaran bagi siswa dan pelatihan, mencakup aspek pengetahuan, keterampilan dan sikap.

2. Menjamin strategi asesmen sejalan dengan capaian pembelajaran.

3. Menyusun aktivitas dan tugas pembelajaran secara progresif agar siswa dapat mematok target pengetahuan, keterampilan dan sikap yang dibangun dalam proses belajarnya.

a. menyajikan materi yang mendukung belajar aktif;

b. dalam durasi pembelajaran, pengetahuan dibangun mulai dari yang mendasar lalu meningkat menuju keterampilan pada tingkat yang lebih tinggi seperti aplikasi, integrasi dan analisis.

4. Menjamin keseimbangan antara kehadiran guru memberi materi, interaksi sosial, tantangan atau beban kognitif.

(Yudhanto et al., 2015)

Permasalahan mitra (Sekolah Islam Ya bunayya dan Faza Islamic School), terkait dengan variasi platform pembelajaran yang dapat membantu mewujudkan edaran kemdikbud no 4 tahun 2020. Serta dapat menghasilkan pembelajaran daring yang baik dan bermutu. Dengan menggunakan media teknologi informasi sebagai platform.

Kemajuan teknologi komunikasi dan informasi seperti yang terjadi saat ini telah mengubah paradigma belajar dan pembelajaran. Serta memberikan banyak sekali pilihan Platform media pendukung belajar. Kemajuan teknologi komunikasi dan informasi telah membuat guru tidak 
lagi harus berperan sebagai pengajar dan sumber informasi pengetahuan semata, tetapi juga menjadi pengelola dan pengembang program pembelajaran yang dapat membantu siswa mencapai kemampuan dan kompetensi yang dibutuhkan. (Pribadi, 2017)

Permasalahan spesifik pada mitra yakni belum adanya pelatihan atau workshop penggunaan Platform media pendukung belajar yang dapat memanage sebuah kelas utuh layaknya kelas belajar di sekolah, terdapat interaksi bolak balik. Serta memiliki umpan balik atas aktivitas siswa. Sehingga diharapkan dapan menghasilkan pembalajaran daring yang baik dan bermutu.

Untuk itu, kami menawarkan solusi kepada mitra memberikan pelatihan berupa workshop, dimana dengan workshop ini para guru dapat langsung melakukan aktivitas ujicoba dan interaksi dengan pantauan para turor. Sehingga harapannya setelah kegiatan ini mereka benarbenar mampu menggunakan platform pembelajaran yang diberikan dan dipelajari

\section{METODE KEGIATAN}

Metode yang di berikan untuk menyelesaikan permasalahan dari mitra adalah memberikan pelatihan berupa workshop. Penggunaan platform LMS (Learning Management system) Edmodo dan Google Classroom. Pelatihan dan workshop ini dilakukan selama satu minggu.

Dengan objek mitra adalah guru pada Sekolah Islam Ya bunayya dan Faza Islamic School. Yang dilakukan dalam beberapa tahapan.

Pada tahap awal kegiatan pengabdian ini kami lakukan observasi kepada guru - guru mitra dan orang tua siswa mitra. Melalui kuesioner online dan wawancara langsung dan tidak langsung, untuk mengetahui secara pasti kondisi dan permasalahan yang ada pada sekolah mitra.

Di pertemuan awal peserta diberikan materi pemahaman tentang persiapan atau pengetahuan awal berupa metode - metode pembelajaran yang dapat diterapkan, prinsip prinsip dalam pembelajaran daring. Kemudian dilanjutkan pemberian materi singkat tentang fitur LMS Edmodo dan Google classroom, Kesemua materi ini diberikan secara daring melalui aplikasi zoom. Pada hari berikutnya peserta diminta praktek langsung penggunaam LMS Edmodo dan Google classroom. Dengan metode diskusi secara langsung via zoom dan

grup diskusi dan bimbingan intensif kepada peserta. Juga di dokumentasikan via live streaming youtube di alamat : https://www.youtube.com/watch?v=G1Pogn MeYDO

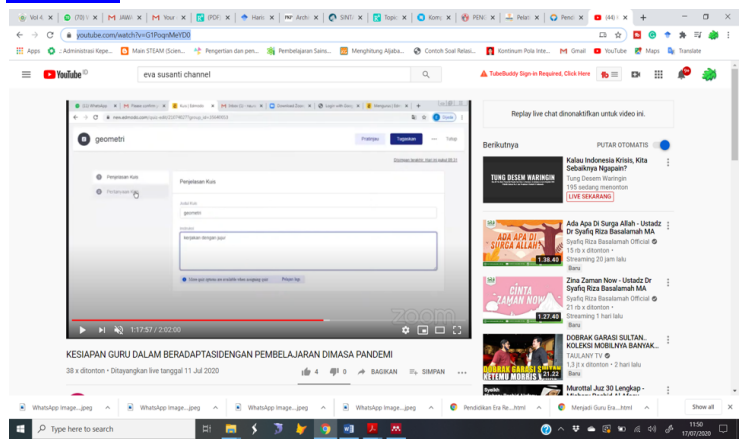

Gambar 1. Live Streaming Youtube Kegiatan

\section{HASIL \& PEMBAHASAN}

Pelaksanaan kegiatan pengabdian dilaksanakan secara online karena kondisi pandemi yang masih melarang kegiatan yang mengumpulkan banyak orang. Kegiatan ini dilaksanakan menggunakan aplikasi teleconference yakni zoom pada saat pemaparan materi, menggunakan whatsapp grup pada saat diskusi dan sharing kendala kendala. Menggunakan zoom terstruktur pada saat praktik penggunaan aplikasi $L M S$.

Di awal memulai kegiatan kami terlebih dahulu memberikan link registrasi kepada peserta untuk mendapatkan data peserta dan data awal sebelum pelaksanaan kegiatan. Di dapati data sebagai berikut :

Table 1. Jumlah peserta

\begin{tabular}{|l|l|c|}
\hline No & Sekolah & Jumlah Peserta \\
\hline 1 & Faza Islamic Shool & 11 \\
\hline 2 & $\begin{array}{l}\text { Sekolah Ya } \\
\text { Bunayya }\end{array}$ & 9 \\
\hline
\end{tabular}

Table 2. Respons Peserta terhadap diadakannya workshop

\begin{tabular}{|l|l|c|}
\hline Indikator & Respons & Persentase \\
\hline $\begin{array}{l}\text { Motivasi } \\
\text { Kengikuti }\end{array}$ & $\begin{array}{l}\text { Menambah } \\
\text { Pengetahuan }\end{array}$ & $100 \%$ \\
\hline $\begin{array}{l}\text { Yang } \\
\text { dibutuhkan }\end{array}$ & $\begin{array}{l}\text { Pelatihan } \\
\text { penggunaan } \\
\text { Media ICT }\end{array}$ & $85 \%$ \\
\hline Kesiapan & Siap & $100 \%$ \\
\hline
\end{tabular}

Dengan melihat hasil respons yang baik ini, pengabdi tidak perlu memberikan terapi 
khusus untuk meningkatkan motivasi peserta sebelum belajar karena mereka telah betul betul ingin belajar. Lalu pengabdi memulai kegiatan dengan memberikan materi awal.
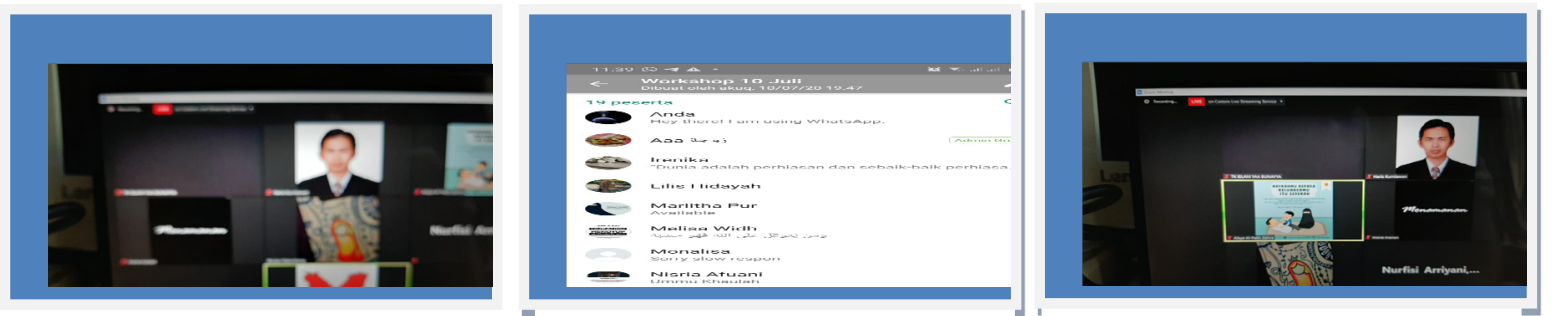

Gambar 2. Foto Kegiatan Zoom dan diskusi grup Wa

Ada 3 materi yang pengabdi berikan kepada peserta yakni : (1) Bagaimana menjadi guru yang siap di kondisi apapun, khususnya pada masa pandemi COVID-19. (2) Tutorial Penggunaan LMS Edmodo. (3) Tutorial Penggunaan LMS Google classroom.

Pada materi (1) Bagaimana menjadi guru yang siap di kondisi apapun, khususnya pada masa pandemi COVID-19. Pengabdi memaparkan bahasan tentang apa yang mesti seorang guru ketahui agar mereka siap dalam situasi apapun. Pengabdi memaparkan bahwa yang mesti diketahui oleh seorang guru agar siap dalam situasi apapun adalah (I) mengetahui dan memahami kondisi lingkungan belajar, yakni kondisi siswa pada saat pandemi COVID19. Kondisi lingkungan rumah dan keluarga siswa. (II) mengetahui dan memahami kebijakan pemerintah terkait kondisi pandemi COVID-19. Selain kurikulum guru juga mesti memahami kebijakan pemerintah terkait kondisi yang terjadi.

Kedua point tersebut di tujukan agar peserta workshop dapat menentukan sikap yang mesti mereka lakukan untuk beradaptasi dengan keadaan yang ada. Sehingga apa yang mereka lakukan pada proses belajar mengajar akan menjadi lebih siap. Dengan mengetahui dan memahami 2 point diatas, peserta workshop akan berkreasi dan berinovasi dalam merancang pembelajaran yang akan mereka lakukan, sesuai dengan kondisi. Yang akan berbeda perlakuaan disetiap kondisi kelas dan kondisi pelajaran.

Setelah mengetahui dibutuhkan strategi pembelajaran yang berbeda untuk masing masing kondisi, peserta di beri materi tentang bagaimana cara menentukan strategi yang tepat dengan 3 Azas yakni (1) Apa, materi apa yang akan di ajarkan. (2) Siapa, kepada siapa materi akan diajarkan. (3) Bagaimana, bagaimana mengajarkan materi tersebut kepada objek ajar tersebut agar informasi dan aktivitas yang dilakukan tepat sasaran.
Yang kesemua hal diatas harus diusung dengan tiga prinsip antara lain (1) Membangun, strategi yang digunakan mesti dapat membangun pengetahuan siswa melalui aktivitas yang mereka lakukan. (2) Menginspirasi, melakukan proses pembelajaran dengan cara menginspirasi siswa melalui contoh yang diberikan oleh guru. (3) Bersama sama, melakukan aktivitas pembelajaran secara bersama - sama, tidak hanya memberikan tugas kepada siswa.

Pada Materi ke (2) Tutorial Penggunaan LMS Edmodo. Pengabdi memberikan materi tutorial merancang pembelajaran dengan memanfaatkan LMS Edmodo dengan prinsip - prinsip yang dipaparkan pada materi pertama. Pengabdi memaparkan secara rinci detail fitur - fitur yang terdapat pada LMS Edmodo. Baik dari sisi akun user sebagai guru ataupun user sebagai siswa. Dengan tujuan agar peserta Workshop benar benar memahami keterpakaian fitur yang dipakai, sehingga saat dibuat mereka mengetahui tampilan yang ada saat menjadi murid.

Kemudian peserta diberikan tugas untuk membuat sebuah kelas untuk satu mata pelajaran, lengkap dari penyampaian materi, aktivitas siswa hingga evaluasi pembelajaran.

$$
\text { Pada Materi ke (2) Tutorial }
$$
Penggunaan LMS Google Classroom. Pengabdi memberikan materi tutorial merancang pembelajaran dengan memanfaatkan LMS Google Classroom dengan prinsip - prinsip yang dipaparkan pada materi pertama. Pengabdi memaparkan secara rinci detail fitur - fitur yang terdapat pada $L M S$ Google Classroom. Baik dari sisi akun user sebagai guru ataupun user sebagai siswa. Dengan tujuan agar peserta Workshop benar benar memahami keterpakaian fitur yang dipakai, sehingga saat dibuat mereka 
mengetahui tampilan yang ada saat menjadi murid.

Setelah semua materi disampaikan pada hari pertama, selanjutnya pengabdi memantau tugas yang diberikan kepada peserta, serta membimbing peserta hingga betul betul memahami $L M S$ yang telah di berikan. Dengan waktu pembimbingan selama 5 hari. Sejak pemberian tugas.

Dari semua kegiatan yang dilakukan didapati bahwa guru peserta workshop mendapatkan pilihan platform yang dapat digunakan didalam pembelajaran daring dimasa pandemi COVID-19. Dan peserta dapat menerapkan azas dan prinsip dalam mempersiapkan diri untuk menjadi guru yang betul - betul siap untuk menerapkan pembelajaran daring yang baik dan bermutu.

Karena dimasa pandemic COVID-19 ini pendidik dituntut untuk mampu menyesuaikan diri dan berinovasi dengan memanfaatkan teknologi yang diharapakan pada era pendidikan 4.0. (Asih Theffidy, 2020)

Dengan adanya workshop ini guru diharapkan dapat membiasakan diri dengan pembelajaran daring atau pembelajaran jarak jauh. Karena kendala yang didapati dilapangan adalah guru belum terbiasa dengan budaya pembelajaran jarak jauh. (Purwanto et al., 2020)

\section{KESIMPULAN \& SARAN}

\section{Kesimpulan}

Pengabdian yang dilakukan oleh LPPM Univeristas Tamansiswa ini merupakan sebuah usaha untuk memberikan solusi kepada sekolah mitra Sekolah Islam Ya bunayya dan Faza Islamic School dalam mempersiapkan guruguru mereka dalam menghadapi penyesuaian dalam proses pembelajaran dimasa pandemi COVID-19. Dengan memberikan beberapa pilihan platform pembelajaran online dan azasazasnya. Yang hasilnya dapat memicu motivasi dan kreativitas guru untuk berinovasi dalam menyiapkan pembelajaran.

\section{Saran}

Untuk memicu dan mewujudkan pembelajaran yang bervariasi dan selalu beradaptasi dengan keadaan yang terjadi. Maka guru harus selalu mengupgrade pengetahuannya baik pengetahuan tentang kurikulum dan kebijakan - kebijakan pemerintah, guru juga mesti mengupgrade pengetahuannya tentang metode, pendekatan dan pengetahuan di bidang pendidikan era 4.0
Kebijakan Belajar Dari Rumah Dalam Masa Darurat Covid-19. Info Singkat;Kajian Singkat Terhadap Isu Aktual Dan Strategis, XII(7/I), 6. http://berkas.dpr.go.id/puslit/files/info_si ngkat/Info Singkat-XII-7-I-P3DI-April2020-1953.pdf

Asih Theffidy, S. G. (2020). Guru Di Era Revolusi Industri 4.

Kemdikbud. (2020). Panduan Pembelajaran Jarak Jauh Tujuan Bagi GURU selama Sekolah Tutup dan Pandemi Covid 19 dengan semangat Merdeka Belajar. Dirjen Guru dan Tenaga Kependidikan.

Pribadi, B. A. (2017). Media dan Teknologi dalam Pembelajaran (1st ed.). KENCANA.

Purwanto, A., Pramono, R., Asbari, M., Santoso, P. B., Wijayanti, L. M., Choi, C. H., \& Putri, R. S. (2020). Studi Eksploratif Dampak Pandemi COVID-19 Terhadap Proses Pembelajaran Online di Sekolah Dasar. EduPsyCouns: Journal of Education, Psychology and Counseling, 2(1), 1-12. https://ummaspul.ejournal.id/Edupsycouns/article/view/397

Santoso, D. H., \& Santosa, A. (2020). COVID19 DALAM RAGAM TINJAUAN PERSPEKTIF (D. H. Santoro (ed.)). MBridge Press.

Yudhanto, Y., Yang, Y., Cornelius, L. F., Sulistyanto, M. P. T., Nugraha, D. A., Sari, N., Karima, N., Asrori, W., Pambudi, A., Njeru, A. M., Omar, M. S., Yi, S., Paracha, S., Wannous, M., Junaidi, A., Iot, D., Daya Negeri Wijaya, Davies, T., Cahyono, G. H., ... Qomarudin, M. N. (2015). Esensi Pengembangan Pembalajaran Daring. Proceedings of the 2017 IEEE International Conference on Applied System Innovation: Applied System Innovation for Modern Technology, ICASI 2017, 1(3), 131. https://doi.org/10.1109/ICASI.2017.7988 469 